\section{New record of Psyllaephagus phylloplectae Sushil \& Khan (Hymenoptera: Chalcidoidea: Encyrtidae) from Karnataka, with notes on its taxonomy and host, Megatrioza hirsuta (Crawford) (Hemiptera: Triozidae)}

\author{
Ankita Gupta ${ }^{1}$, V. Naveenkumar ${ }^{2}$ \& J. Poorani ${ }^{3}$ \\ 1,2,3 Project Directorate of Biological Control, P.B. No. 2491, H.A. \\ Farm Post, Bellary Road, Bangalore, Karnataka 560024, India \\ Email: ${ }^{1}$ ankitagupta9@ rediffmail.com; ${ }^{3}$ pooranij@gmail.com
}

During surveys for chalcidoids in southern India, we came across Psyllaephagus phylloplectae Sushil \& Khan (1995) parasitizing Megatrioza hirsuta (Crawford) (=Trioza hirsuta, Phylloplecta hirsuta) (Hemiptera: Psylloidea: Triozidae) causing leaf galls on Terminalia spp. in Karnataka. Brief diagnostic and biological notes are provided for the parasitoid and its host in this Note. The specimens we studied are permanently preserved in the reference collections of the Project Directorate of Biological Control, Bangalore.

\section{Symptoms of damage by Megatrioza hirsuta and its diagnostic features}

Megatrioza hirsuta is a major pest of Terminalia spp. Mathur (1949), and Beeson (1941) provided detailed accounts of the immature stages and the nature of damage caused. The nymphs of $M$. hirsuta cause distortion and folding of the leaves. One or both margins of the leaves are rolled into the midrib on the upper surface (Image 1) and the rolled margins gradually become thickened and hard like a gall and turn pink or mauve; sometimes the whole leaf becomes folded and thickened (Image 2). The size and position of the galls vary, and occasionally the leaves are spirally distorted. Several nymphs remain sheltered in these rolled leaves and are often covered with copious secretions of white wax (Images 3-4). Large round drops of liquid excrement, with their surface coated with white wax and

Date of publication 26 March 2009

ISSN $0974-7907$ (online) | $0974-7893$ (print)

Editor: T.C. Narendran

\section{Manuscript details:}

Ms \# 01872

Received 13 October 2007

Final revised received 16 January 2008

Finally accepted 21 February 2008

Citation: Gupta, A., V. Naveenkumar \& J. Poorani (2009). New record of Psyllaephagus phylloplectae Sushil \& Khan (Hymenoptera: Chalcidoidea: Encyrtidae) from Karnataka, with notes on its taxonomy and host, Megatrioza hirsuta (Crawford) (Hemiptera: Triozidae). Journal of Threatened Taxa 1(3): 174176.

Copyright: (c) Ankita Gupta, V. Naveenkumar \& J. Poorani 2009. Creative Commons Attribution 3.0 Unported License. JoTT allows unrestricted use of this article in any medium for non-profit purposes, reproduction and distribution by providing adequate credit to the authors and the source of publication.

Acknowledgements: This study was undertaken at Project Directorate of Biological Control, Bangalore under the Network Project on Insect Biosystematics funded by Indian Council of Agricultural Research, New Delhi.

OPEN AGCESS | FREE DOWNLOAD fragments of wax threads, are also present inside the rolled leaves (Image 5). The adults (Image 6) are light brown and covered with hairs, with darker brown markings on dorsulum, long antenna with segments apically black, and hyaline, transparent wings with a prominent, large triangular marking near tip of clavus. The adults are described in detail and illustrated by Mathur (1975).

\section{Psyllaephagus phylloplectae Sushil \& Khan}

The genus Psyllaephagus Ashmead (Hymenoptera: Chalcidoidea: Encyrtidae) is represented by 11 species in India (Hayat 2006), with one indeterminate species included in Hayat's key to the Indian species. The members of the genus are known to be primary or secondary endoparasitoids of the nymphs of Psyllidae sensu lato (Hemiptera) (Noyes \& Fallahzadeh 2005; Hayat 2006), with the sole exception of $P$. solanensis Sushil and Khan (1995), which was described as a parasitoid of indeterminate coccids on olive.

Karnataka is a new distribution record for the parasitoid, $P$. phylloplectae, which is presently known only from Uttaranchal (Sushil \& Khan 1995), on the same host. We provide a brief diagnostic account with notes on its morphology with photographs of the adult female and male.

\section{Diagnosis of P. phylloplectae (Images 7-8)}

Female: (Image 7) Length: $2.50 \mathrm{~mm}$. Head and mesosoma (thorax) brilliant metallic green, shining; metasoma (gaster) medially dark brown to black, lateral margins of tergites metallic green; antennae brownish-yellow with scape apically and basally yellowish, median $3 / 5^{\text {th }}$ dark brown, F $1-$ F6 brownish-yellow, club yellowish-brown, with apical two segments darker; legs whitish, fore coxae white, middle coxae basally dark metallic green, apically and ventrally whitish-yellow, hind coxae dark metallic green, apically narrowly whitish; tegulae yellowish. Antenna with scape flattened and expanded, $2.2 \mathrm{x}$ as long as wide, F1-F6 longer than wide, slightly but gradually increasing in width apically; club 3-segmented, compact, $1.85 \mathrm{x}$ longer than wide, blunt at apex. Mesoscutum wider than long, more or less uniformly punctate with strong, reticulate sculpture in interspaces; scutellum longer than wide, with slightly larger and sparser punctures and reticulate sculpture. Forewing with marginal vein and postmarginal vein distinctly shorter than stigmal vein. Metasoma elongate triangular, apically pointed.

Male: (Image 8) Length: 2.10-2.30mm. Resembles female, but antennae distinctly sexually dimorphic; scape yellow, cylindrical, with outer and inner margins sinuate, with a $\mathrm{T}$ shaped dark brown marking apically extending to distal $2 / 3^{\text {rd }}$ in dorsal inner half; pedicel yellow, obtriangular, apically slightly brownish. FI-III yellowish, basally dark brown, distinctly transverse; FIV-VI narrowly yellow, with basal and lateral margins brown, longer than broad; club more or less suffused with brown, shorter than F5 and F6 combined.

Material studied: 5 females, 1 male ( 2 females, 1 male deposited at AMU, Aligarh); Karnataka: Hosakote, ex. Leaf galls on Terminalia sp., 6.x.06, Kaomud; 5 females, 2 males, Karnataka: Karasawadi, ex: Megatrioza hirsuta (Crawford) on leaf galls of Terminalia sp., 12.vii.07, Naveenkumar.

The specimens sent to Dr. Mohammad Hayat, Aligarh 


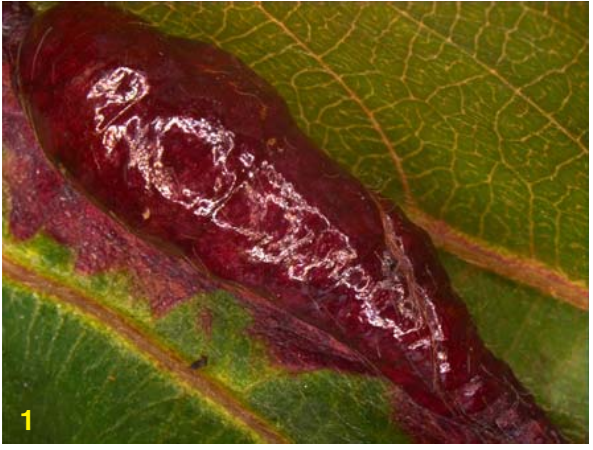

Image 1. Marginal gall on leaf of Terminalia sp.

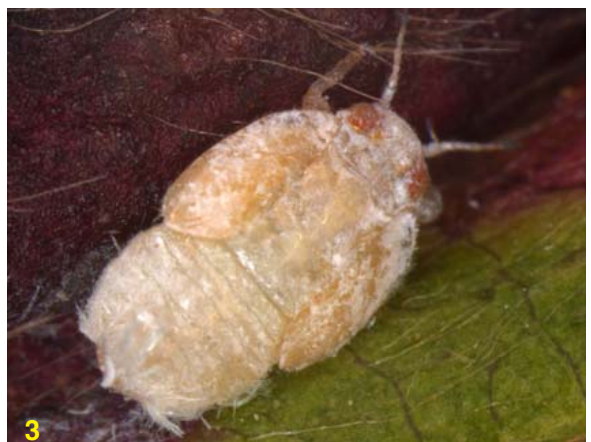

Images 3-4. Nymph of Megatrioza hirsuta

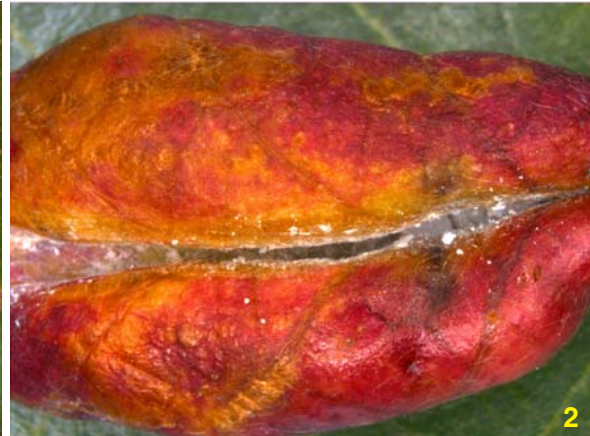

Image 2. Whole leaf rolled into a galllike structure

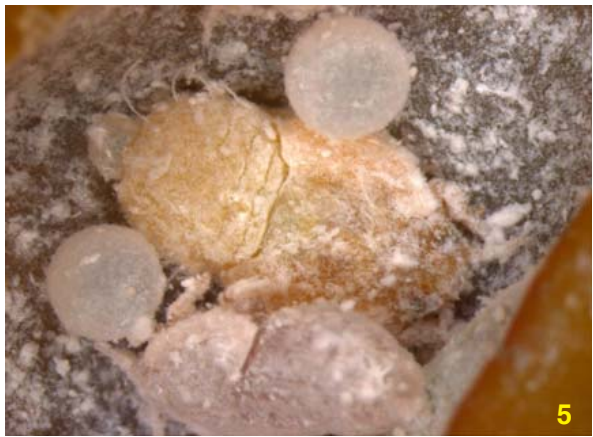

Image 5. Nymphs and honey dew globules inside the gall

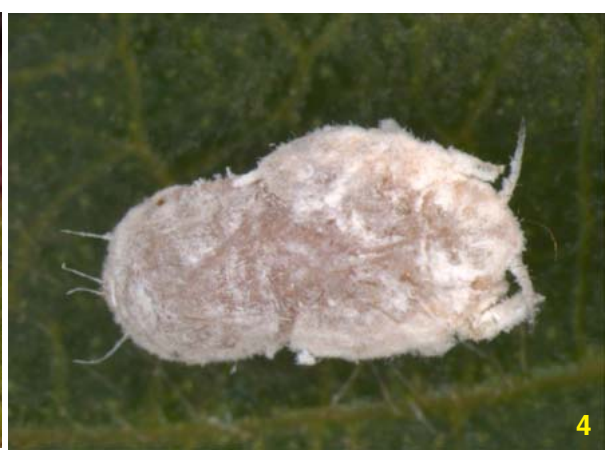

4

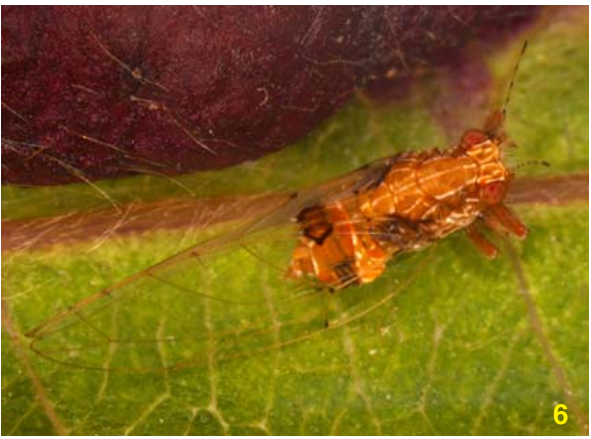

Image 6. Adult of Megatrioza hirsuta

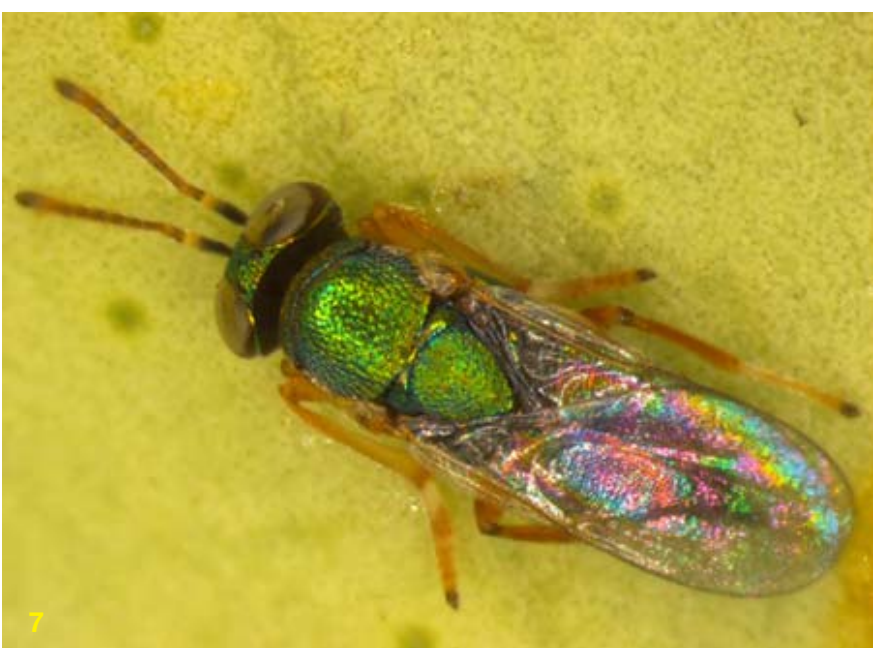

Images 7-8. Psyllaephagus phylloplectae. 7 - Female; 8 - Male

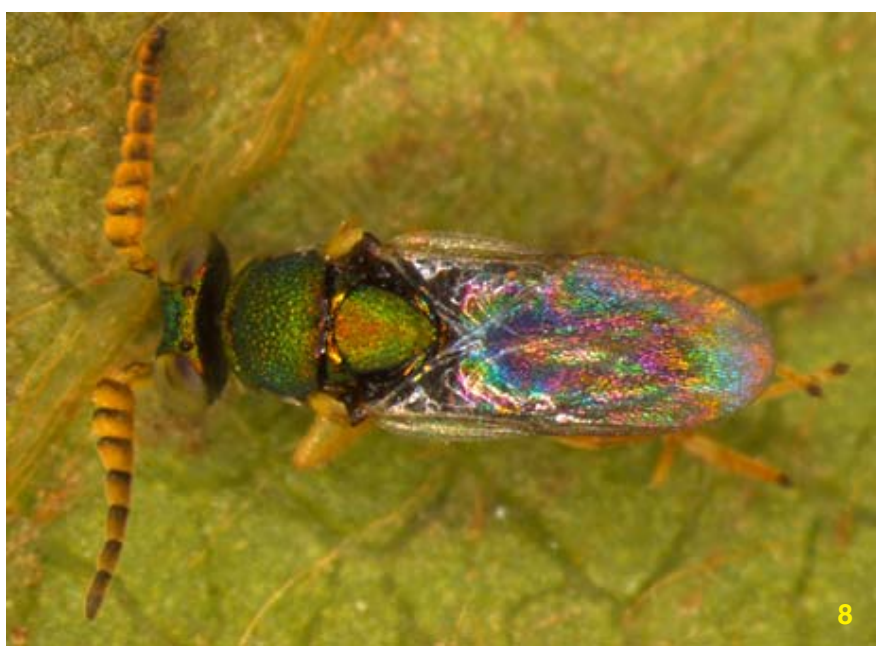

8
Muslim University, were retained by him for his personal collection and registration numbers were not given for these by us. The specimens we studied are permanently preserved in the reference collections of the Project Directorate of Biological Control, Bangalore, as mentioned in the MS with registration number as follows: PDBC AN ENC-20, 21 and 22, for the threefemales with date of collection as 6.x.06. For five females with collection date 12.vii.07, the numbers are PDBC AN ENC- 23, 24, 25, $26 \& 27$ and for two males - PDBC AN ENC- 28 and 29 respectively.

\section{Discussion}

This species agrees with the description provided by Sushil
\& Khan (1995) for P. phylloplectae except for the following variations: in female, pedicel not more than twice longer than wide; fore coxae completely yellowish-white, mid coxae basally dark metallic green, apically and ventrally whitish; hind coxae dark metallic green with only apices narrowly whitish. Hayat (2006), in his key to the females of Indian Psyllaephagus, indicated that the colour of the legs, including the coxae, was pale yellow to white, based on the original description (Sushil \& Khan 1995).

In the original description, the postmarginal vein on the fore wing is described as approximately the same size as that of stigmal vein, but in the illustration, the stigmal vein is clearly much longer. In the specimens we have examined, the 
postmarginal vein is distinctly shorter than stigmal vein.

\section{References}

Beeson, C.F.C. (1941). The Ecology and Control of the Forest Insects of India and the Neighbouring Countries. Vasant Press, Dehra Dun, 1007pp.

Hayat, M. (2006). Indian Encyrtidae (Hymenoptera: Chalcidoidea). Department of Zoology, Aligarh Muslin University, India, 496pp.

Mathur, R.N. (1949). On the immature stages of some Psyllidae. Indian Journal of Entomology 8(2): 231-233.

Mathur, R.N. (1975). Psyllidae of the Indian Subcontinent. Indian Council of Agricultural Research, New Delhi, 429pp.
Noyes, J.S. \& M. Fallazadeh (2005). Psyllaephagus zdeneki sp. nov. (Hymenoptera: Encyrtidae) from Iran, a parasitoid of Euphyllura pakistanica (Hemiptera: Psyllidae). Acta Societatis Zoologicae Bohemoslovemocae 69: 203208.

Sushil, S.N. \& M.A. Khan (1995). Two new species of Psyllaephagus (Hymenoptera: Encyrtidae) from northern India. Journal of Insect Science 8: 20-23. 